\title{
Effect of Glass/Carbon Ratios and Laminate Geometry on Flexural Properties of Glass/Carbon Fiber Hybrid Composites
}

\author{
Md. Hasan Ikbal, Wang Qingtao and Li Wei* \\ College of Textiles, Key Laboratory of Textile Science and Technology \\ Donghua University \\ Shanghai 201620, China \\ e-mail:liwei@dhu.edu.cn
}

\begin{abstract}
Hybridization of glass fibers into carbon fibers could be an effective way to improve the failure strain problems of pure carbon composites and to reduce vehicle weight without excessive cost. Relative glass/carbon ratios significantly influences the flexural properties and laminate geometry further optimizes them. Hybrid composite laminates tend to fail more gradually when the relative carbon fiber content is much lower. Carbon fibers fail first due to having a low strain-to-failure resulting in stress drops and the composite continues extending until glass fiber fails finally and hence the catastrophic failure behaviour can be avoided.
\end{abstract}

Keywords-hybrid composites; carbon fiber; glass fiber; flexural properties; hybrid effect; finite element analysis

\section{INTRODUCTION}

Like most materials, fiber reinforced polymers (FRP) face the strength versus toughness dilemma. For example in the case of carbon fiber (CF) being well known for having superior strength and stiffness; but these high strength and stiffness come at the expense of its low toughness. Meaning that the CF has a very low strain-to-failure and is regarded as a disadvantage for the use of carbon fiber reinforced polymers (CFRP) when utilized as structural members that will be subjected to compressive and or/flexural loading. On the other hand, glass fibers (GF) which have much lower strength than carbon fibers but are much tougher due to having a higher strain-to-failure. It has been proved that incorporation of GF into $\mathrm{CF}$ is possible with a view to improve the failure strain of CFRP, turning the materials to some kind of hybrids. Apart from the toughness issue, CF are also very expensive which is regarded as the main drawback why CFRP are only popular in aero industries and in concept and luxury cars where weight saving is considered to be the primary concern. GF are cheaper than $\mathrm{CF}$ and the glass fiber reinforced polymers (GFRP) have been increasingly used to replace steel in automotive industry . The use of CFRP could yield a $40-60 \%$ weight reduction ; but its adoption rate still remains low. Hybridization of GF into CF selectively could be an effective way to reduce vehicle weight without excessive cost .

Flexural properties of hybrid composites are highly dependent on the layup, since the stress at the neutral line is zero. Therefore, it is possible to increase the flexural strength a hybrid composite by placing CF in the outer ply/on tension side and GF in the inner ply/on compression side (as is utilized for this study) which single fiber reinforced polymers alone cannot offer. Though this strategy seems to potentially lead to large hybrid effects. It has been reported by the authors that the flexural strengths of glass/carbon intra-layer hybrids are $40 \%$ and $9 \%$ than full CFRP and GFRP and the strength was even higher than the results predicted by both finite element analysis (FEA) and classic lamination theory (CLT) . In another work the authors noticed that the glass fibers failed on the tension side, while the carbon fibers mainly failed on the compression side. In a similar work it was reported that the highest flexural strength in carbon/glass hybrids was achieved at a relative content of $12.5 \%$ glass fibers, all of which are placed on the compression side . Hence, a symmetric layup is not the optimal design for a hybrid composite that will subjected to flexural loads. Many authors investigated the flexural properties of natural fibers based hybrids and as expected, the performance of the hybrids lie in between the performances of both fibers .

In the present study, unidirectional non-crimp carbon, glass and glass/carbon hybrid fabrics with epoxy resin matrix have been used for fabricating hybrid laminates. Effects of different glass/carbon ratios and two different laminate geometries (intra-layer and inter-layer) on the flexural response were investigated experimentally and computationally. Scanning electron microscopy (SEM) was used to investigate the damage morphology.

\section{EXPERIMENTAL PROCEDURE}

\section{A. Materials, manufacturing and, mechanical test}

Unidirectional noncrimp plain carbon (T620S) and plain E-glass and glass/carbon hybrid fabrics were used to reinforce epoxy (EPIKOTETM MGS ${ }^{\circledR}$ RIMR135) cured with hardener. Vacuum assisted resin infusion (VARI), Figure 1(b), was used to fabricate eight different laminates with five different glass/carbon ratios. Composite laminates were cured in a closed chamber oven at a constant pressure of $0.1 \mathrm{MPa}$ and constant temperature of $60{ }^{\circ} \mathrm{C}$ for $6 \mathrm{hrs}$. Laminates were categorized into three groups according to different compositions. Each of these groups (I, II, and III) comprises two specimens; intra-layer hybrid (An) and interlayer hybrid (Bn), where $n=1,2,3$, Figure 1(a). The overall fiber volume fractions of the composites are furnished in Table I. The ASTM D790 standard was used for the threepoint bend test using an Instron 550R universal 
(a)

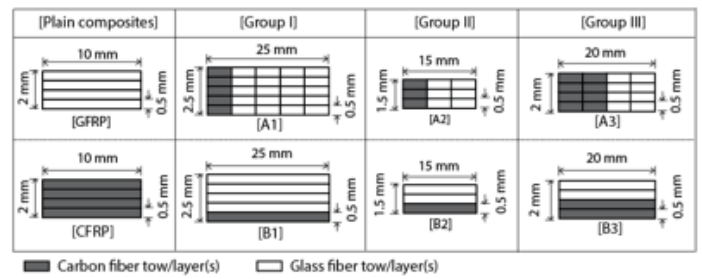

(b)

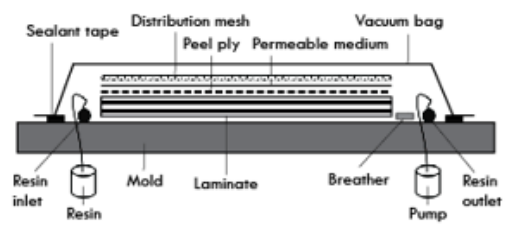

Figure 1. Laminate geometry and schematic illustration of VARI process.

testing machine at a span-to-depth ratio of 40 . The average loading rate was $0.05 \mathrm{~mm} / \mathrm{sec}$. The thickness of the cured composite was between $1.5 \mathrm{~mm}$ and $2.5 \mathrm{~mm}$. The specimen dimension was $120 \mathrm{~mm} \times(10 / 15 / 20 / 25) \mathrm{mm}$. At least five tests were carried out for each specimen. The SEM micrographs were taken from a Hitachi TM3000 microscope.

\section{B. Finite element analysis}

The flexural behaviour under three point bending was further studied using a commercial software package ABAQUS/Standard (Version 6.11). The parts used for the analysis were $3 \mathrm{D}$ deformable solid of extrusion type. The materials properties input to the FE models calculation were the density, mechanical properties and the Hashin damage criteria. The lamina properties including the longitudinal modulus $E_{11}$, the transverse moduli $\mathrm{E}_{22}$ and $E_{33}$, and the shear moduli $G_{12}, G_{13}$ and $G_{23}$ were derived by Hashin's model . Each part was assigned the respective material properties and assembled together. Meshing of the model was done with the eight-node reduced integration element (C3D8R). The element size was kept constant for all specimens to $0.5 \mathrm{~mm}$. Due to Hashin formulation do not consider the failure by delamination, a surface to surface cohesive zone modeling was created at the interfaces and the quadratic traction damage initiation criterion for cohesive surfaces was included in the Hashin damage models. Appropriate boundary conditions were applied and the specimens were loaded (at a rate of $0.05 \mathrm{~mm} / \mathrm{sec}$ ) to mimic the experiments.

\section{RESULTS AND DISCUSSION}

The flexural stress-strain curves for all eight types of composite laminates are shown in Figure 2 and the calculated mechanical property data are furnished in Table I. As expected, CFRP had the highest flexural strength and lowest flexural strain, and the opposite is true for GFRP. The effect of proportion of CF content is clearly seen, A3 and B3 had the highest flexural strength among all hybrid laminates accounting $78.88 \%$ and $75.52 \%$ respectively of that of CFRP. A1 and B1 had the lowest strength among all hybrid laminates accounting $65.23 \%$ and $62.04 \%$ respectively of that of CFRP. Flexural moduli, specific strength and specific stiffness of A3 and B3 were also higher than that of A1 and B1, Table I. Relative proportion of glass/carbon fibers significantly affected the flexural strength and hence is a key parameter in determining the flexural strength. Similar effects could be found in other research work . As the relative proportion of CF content increases, flexural strength and flexural moduli improves. Higher the CF content higher the flexural strength and flexural moduli . In terms of flexural strain, it was seen that composite laminates containing lower proportion of CF exhibited the maximum flexural strains.

At hybrid ratio 0.20, hybrid laminates A1 and B1 had the highest flexural strains among all hybrid laminates accounting $143.03 \%$ and $133.33 \%$ of that of CFRP. At hybrid ratio 0.50 , hybrid laminates $\mathrm{A} 3$ and $\mathrm{B} 3$ had the lowest flexural strain among all hybrid laminates accounting $122.42 \%$ and $115.75 \%$ of that of CFRP. In other words, there was a gain in flexural strains for all hybrid laminates when compared to that of CFRP and this percentage enhancement was affected by the relative proportions of the two fiber types. Percentage enhancement in tensile and compressive failure strain was also noticed in some other research works . The linear Rule-of-Mixture (RoM) was used for calculating the flexural strength. Denoting the proportion of carbon fiber content of all fiber reinforcement is $r$, the Young's modulus can be expressed using the simple RoM as:

$E_{H}=\left[\left(r \times E_{C}\right)+\left\{(1-r) \times E_{G}\right\}\right]$

where $E_{H}$ denotes the modulus of hybrid composite, $E_{C}$ denotes the modulus of carbon fiber composite and $E_{G}$ denotes the modulus of glass fiber composite. So the flexural stress $\left(\sigma_{H}\right)$ of the hybrid composite can be expressed as:

$\sigma_{H}=\left[\left(r \times E_{C} \times \varepsilon_{C}\right)+\left\{(1-r) \times E_{G} \times \varepsilon_{G}\right\}\right]$

where $\varepsilon_{C}$ and $\varepsilon_{G}$ are the flexural strains of CFRP and GFRP.

As it can be seen from Figure 3(b), the flexural moduli results agreed well with RoM results, however, the flexural strength exhibited a negative hybrid effect, where the hybridization effect is shown by the negative deviation from the RoM behaviour. Similar kind of effects have been shown by the authors, where analyzing their data negative hybrid effect for flexural strength could be found . Both the experimental and calculated data vs. hybrid ratio are presented in Figure 3. The RoM predictions were able to simulate the experimental trend influenced by proportion of carbon fiber and laminate geometry, however, their calculated results of flexural strength were higher than the experimental results due to shear stress present in the specimens, Figure 3(a). For low span-to-depth ratios and high modulus materials, these shear stresses could be more significant as reported in some literature. In terms of laminate geometry it was seen that the flexural strengths and 
TABle I. Fl Fexural Properties of Composites.

\begin{tabular}{|c|c|c|c|c|c|c|c|c|}
\hline $\begin{array}{l}\text { Composite } \\
\text { laminates }\end{array}$ & $\begin{array}{l}\text { Fiber } \\
\text { volume } \\
\text { fractions }\end{array}$ & $\begin{array}{l}\text { Failure } \\
\text { strain (\%) }\end{array}$ & $\begin{array}{l}\text { Flexural } \\
\text { strength } \\
\text { (MPa) }\end{array}$ & $\begin{array}{l}\text { Modulus } \\
\text { (GPa) }\end{array}$ & $\begin{array}{l}\text { S. strength } \\
\text { (KNm/Kg) }\end{array}$ & $\begin{array}{l}\text { S. stiffness } \\
\text { (MNm/Kg) }\end{array}$ & $\begin{array}{l}\text { Density } \\
\text { (g/cc) }\end{array}$ & $\begin{array}{l}\text { Hybrid } \\
\text { ratio (r) }\end{array}$ \\
\hline GFRP & 0.539 & $2.83( \pm 0.39)$ & $710( \pm 11.25)$ & 25.08 & 486.301 & 17.17 & 1.460 & 0.00 \\
\hline \multicolumn{9}{|l|}{ Group I } \\
\hline A1 & 0.412 & $2.36( \pm 0.31)$ & $783.5( \pm 9.11)$ & 33.19 & 555.094 & 25.04 & \multirow{2}{*}{1.325} & \multirow{2}{*}{0.20} \\
\hline B1 & 0.413 & $2.20( \pm 0.30)$ & $745.2( \pm 8.29)$ & 33.87 & 562.415 & 25.56 & & \\
\hline \multicolumn{9}{|l|}{ Group II } \\
\hline A2 & 0.422 & $2.16( \pm 0.21)$ & $841.0( \pm 8.39)$ & 38.89 & 647.935 & 29.96 & \multirow{3}{*}{1.298} & \multirow{2}{*}{0.33} \\
\hline B2 & 0.426 & $2.08( \pm 0.19)$ & $813.3( \pm 7.77)$ & 39.08 & 626.556 & 30.10 & & \\
\hline \multicolumn{8}{|l|}{ Group III } & \\
\hline A3 & 0.437 & $2.02( \pm 0.23)$ & $947.4( \pm 7.03)$ & 46.90 & 744.210 & 36.84 & \multirow{2}{*}{1.273} & \multirow{2}{*}{0.50} \\
\hline B3 & 0.431 & $1.91( \pm 0.20)$ & $907.0( \pm 10.01)$ & 47.51 & 712.592 & 37.32 & & \\
\hline CFRP & 0.563 & $1.65( \pm 0.15)$ & $1201( \pm 19.34)$ & 72.78 & 970.897 & 58.83 & 1.237 & 1.00 \\
\hline
\end{tabular}
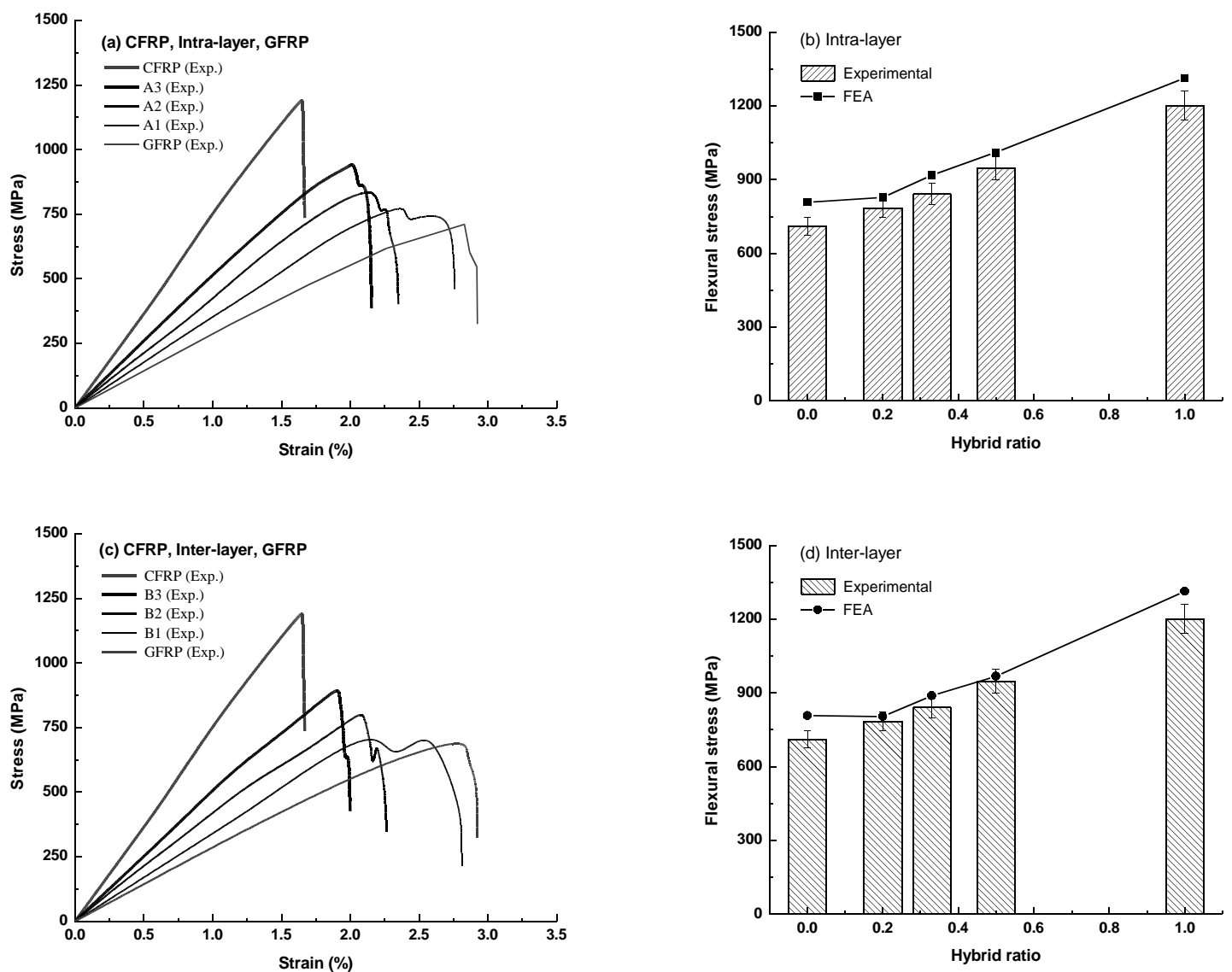

Figure 2. Flexural stress-strain plots of different composite laminates.

flexural strains of intra-layer hybrid laminates, Figure 2(a), were a bit higher than that of inter-layer hybrid laminates, Figure 2(c). In particular, strength of A3 is 1.04 times than that of B3, Table I, and other specimens showed more or same trend.

The reason for this higher flexural strength could be due to intra-layer hybrids having a smaller interface/delaminated area, which should in principle result in better mechanical properties. The reason for the failure strain enhancement could be due to a more gradual failure as it can be seen in Figure 2(a), the last part of the flexural stress-strain diagram is not linear which is to some extent has some sort of plateau near the end.

\section{DAMAGE ANALYSIS}

Under flexural loading common failures include: compressive failure, tensile failure, shear and/or 
delamination. Figure 4(a-b) show the SEM images taken after flexural tests.
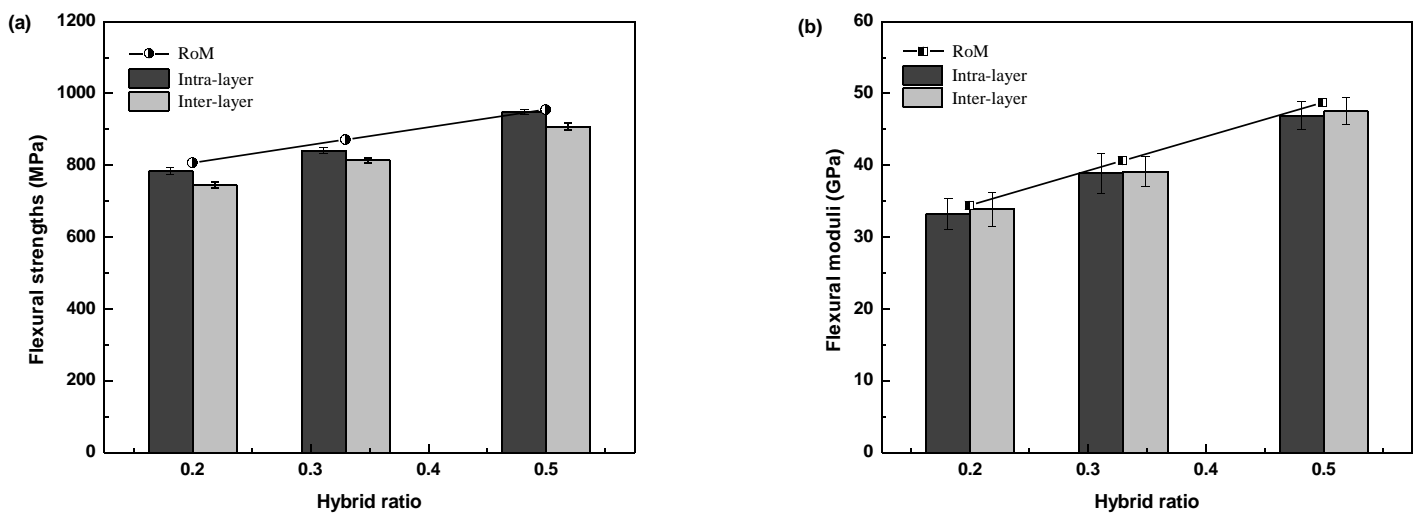

Figure 3. Flexural strength and flexural moduli vs. hybrid ratio.
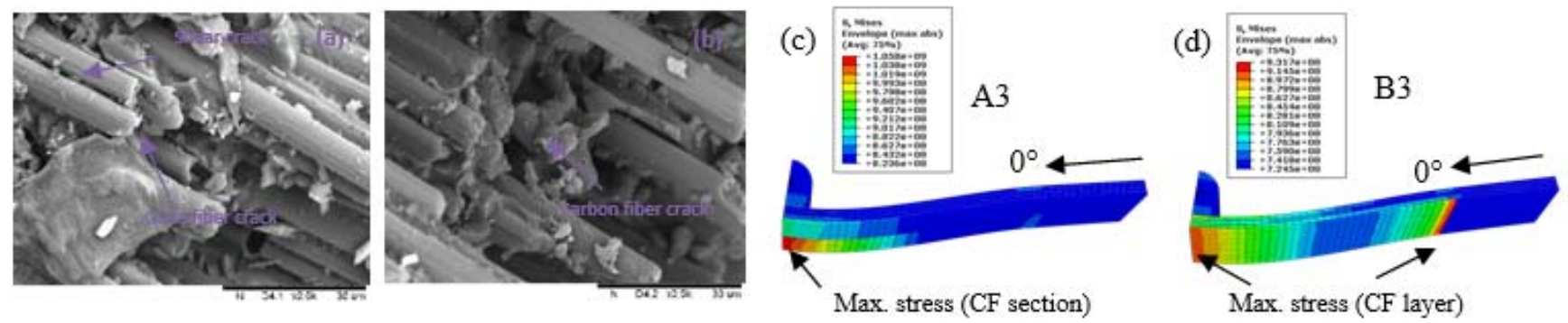

Figure 4. SEM micrographs showing damages and stress contour after flexural tests in FEA.

Specimens were dried and sputtered with gold before observation. Figure 4(a) shows the damage on tension side and Figure 4(b) the damage on the compression side. Kinking at the compression side is noticed and the damage at compression side is prominent. Damage at CF sections are more prominent. Figure $4(\mathrm{c}-\mathrm{d})$ show the maximum stress developed in the CF sections and layers of the specimens after three point bend test in FEA. The maximums stress occurred somewhere at the center of the specimens. Hashin Fiber Tension damage (HSNFTCRT) and Hashin Fiber Compression damage (HSNFCCRT) showed that fiber breakage is prominent at the compression side. Local delamination, not severe, was noticed in the specimens and the interface between similar fiber parts/layers produced a bit more delamination. The predominant failure at compression side could also be due to micro-buckling, shear or splitting.

\section{CONCLUSION}

Eight types of composite laminates, plain CFRP, plain GFRP, three intra-layer hybrids (A1, A2, A3), and three inter-layer hybrids (B1, B2, B3), were produced and flexural properties were investigated under three-pointbending. FEA was used to simulate the flexural behaviour and a fair agreement with the experimental results were found, Figure 2(b) and Figure 2(d). Relative glass/carbon proportions played a crucial role in determining the flexural properties, higher the relative carbon fiber content higher the flexural strength and lower the flexural strain and vice versa. With the same hybrid composition, intra-layer hybrids exhibited better performance when compared to inter-layer hybrid composite laminates.

\section{REFERENCES}

[1] N. Oya, and D.J. Johnson, "Longitudinal compressive behaviour and microstructure of PAN-based carbon fibres," Carbon, 2001, vol. 39(5), pp. 635-645.

[2] M. Shioya, and M. Nakatani, "Compressive strengths of single carbon fibres and composite strands," Composites science and technology, 2000, vol. 60(2), pp. 219-229.

[3] H.A. Al-Qureshi, "Automobile leaf springs from composite materials," Journal of materials processing technology, 2001, vol. 118(1) , pp. 5861.

[4] R. Hosseinzadeh, M.M. Shokrieh, and L.B. Lessard, "Parametric study of automotive composite bumper beams subjected to low-velocity impacts," Composite Structures, 2005, vol. 68(4) , pp. 419-427.

[5] S. Das, "The cost of automotive polymer composites: a review and assessment of DOE's lightweight materials composites research," 2001: Oak Ridge National Laboratory Oak Ridge, TN.

[6] E. Mahdi, A.M.S. Hamouda, B.B. Sahari, and Y.A. Khalid, "Effect of hybridisation on crushing behaviour of carbon/glass fibre/epoxy circular-cylindrical shells," Journal of materials processing technology, 2003, vol. 132(1) , pp. 49-57. 
[7] H. Nordin, and B. Täljsten, "Testing of hybrid FRP composite beams in bending," Composites Part B: Engineering, 2004, vol. 35(1) , pp. 2733.

[8] C. Dong, H.A. Ranaweera-Jayawardena, and I.J. Davies, "Flexural properties of hybrid composites reinforced by S-2 glass and T700S carbon fibres," Composites Part B: Engineering, 2012, vol. 43(2) , pp. 573-581.

[9] J.W. Giancaspro, C.G. Papakonstantinou, and P.N. Balaguru, "Flexural response of inorganic hybrid composites with E-glass and carbon fibers," Journal of Engineering Materials and Technology, 2010, vol. 132(2) , pp. 021005.

[10]C. Dong, and I.J. Davies, "Optimal design for the flexural behaviour of glass and carbon fibre reinforced polymer hybrid composites," Materials \& Design, 2012, vol. 37, pp. 450-457.

[11]R. Petrucci, C. Santulli, D. Puglia, F. Sarasini, L. Torre, and J.M. Kenny, "Mechanical characterisation of hybrid composite laminates based on basalt fibres in combination with flax," hemp and glass fibres manufactured by vacuum infusion, Materials \& Design, 2013, vol. 49, pp. 728-735.

[12] M. Boopalan, M. Niranjanaa, and M.J. Umapathy, "Study on the mechanical properties and thermal properties of jute and banana fiber reinforced epoxy hybrid composites," Composites Part B: Engineering, 2013, vol. 51, pp. 54-57.
[13]P.N. Khanam, M.M. Reddy, K. Raghu, K. John, and S.V. Naidu, "Tensile, flexural and compressive properties of sisal/silk hybrid composites," Journal of Reinforced Plastics and Composites, 2007, vol. 26(10) , pp. 1065-1070.

[14]T.W. Chou, "Microstructural Design of Fibre Composites," Cambridge University Press, Cambridge, 1992.

[15] J. Zhang, K. Chaisombat, S. He, W. Shuai, and H. Chun, "Hybrid composite laminates reinforced with glass/carbon woven fabrics for lightweight load bearing structures," Materials \& Design, 2012, vol. 36, pp. 75-80.

[16]C. Dong, and I.J. Davies, "Flexural and tensile strengths of unidirectional hybrid epoxy composites reinforced by S-2 glass and T700S carbon fibres," Materials \& Design, 2014, vol. 54, pp. 955-966.

[17]C. Dong, and I.J. Davies, "Flexural and tensile moduli of unidirectional hybrid epoxy composites reinforced by S-2 glass and T700S carbon fibres," Materials \& Design, 2014, vol. 54, pp. 893-899.

[18]K.S. Pandya, Ch. Veerraju, and N.K. Naik, "Hybrid composites made of carbon and glass woven fabrics under quasi-static loading," Materials \& Design, 2011, vol. 32(7), pp. 4094-4099.

[19] G. Kretsis, "A review of the tensile, compressive, flexural and shear properties of hybrid fibre-reinforced plastics," Composites, 1987, vol. 18(1), pp. 13-23. 